\title{
NUMI PROTON KICKER EXTRACTION MAGNET TERMINATION RESISTOR SYSTEM*
}

\author{
S. R. Reeves, C. C. Jensen, FNAL, Batavia, IL 60510, USA
}

\begin{abstract}
The temperature stability of the kicker magnet termination resistor assembly directly affects the field flatness and amplitude stability. Comprehensive thermal enhancements were made to the existing Main Injector resistor assembly design to satisfy NuMI performance specifications. Additionally, a fluid-processing system utilizing Fluorinert ${ }^{\circledR}$ FC-77 high-voltage dielectric was built to precisely control the setpoint temperature of the resistor assembly from 70 to $120 \mathrm{~F}$, required to maintain constant resistance during changing operational modes. The Fluorinert ${ }^{\circledR}$ must be continually processed to remove hazardous breakdown products caused by radiation exposure to prevent chemical attack of system components. Design details of the termination resistor assembly and Fluorinert ${ }^{\circledR}$ processing system are described. Early performance results will be presented.
\end{abstract}

\section{INTRODUCTION}

The NuMI kicker magnet performance specifications quickly evolved well beyond the capabilities of the Main Injector kicker design that it was originally based on. Main Injector termination resistors rely on two-phase, convective cooling, insufficient for this application. The NuMI design peak heat load is 300 Watts/termination resistor assembly, 1200 Watts total. Fluorinert ${ }^{\circledR}$ was specified as the heat transfer media due to its high dielectric strength $(40 \mathrm{kV}, 0.1$ " gap). The temperature stability specification for the termination resistors was tightened by a factor of two during the design and fabrication of the system [1]. The heat transfer rates delivered by the prototype did not meet requirements so the entire design was re-evaluated. Thermal enhancements were implemented in the cooling washer, the assembly procedure, and the Fluorinert ${ }^{\circledR}$ processing system.

\section{MAGNET TERMINATION RESISTOR}

The magnet termination resistor (load) assemblies for NuMI are based on an existing Main Injector design that operates at a lower power and repetition rate than required by NuMI (see Figure 1). Each kicker magnet has two loads mounted vertically, one on top, and one in the reverse of the orientation shown on the bottom. Each load is comprised of a set of 10 carefully selected $2 \Omega$ highenergy ceramic composite disc resistors from HVR, model \#W0758B. They were chosen to achieve a $20 \Omega$ resistance at operating temperature.

Silver-plated copper cooling washers, added to transfer the heat generated in the resistor, separate them. The entire assembly is loaded in an arbor press with 2100 pounds to crush the foil and fill gaps caused by the out-of-

*Work supported by Universities Research Association, Inc. under contract DE-AC02-76CH03000 with the U.S. Department of Energy parallelism and surface roughness of the resistors. During the crushing procedure the stack compresses $\sim 0.120 "$. To insure no shifting occurs and to maintain the electrical contact, four 500-pound Belleville washers in conjunction with a G-11 rod are compressed keeping the contact surfaces under a 500-pound load after the crushing force is removed.

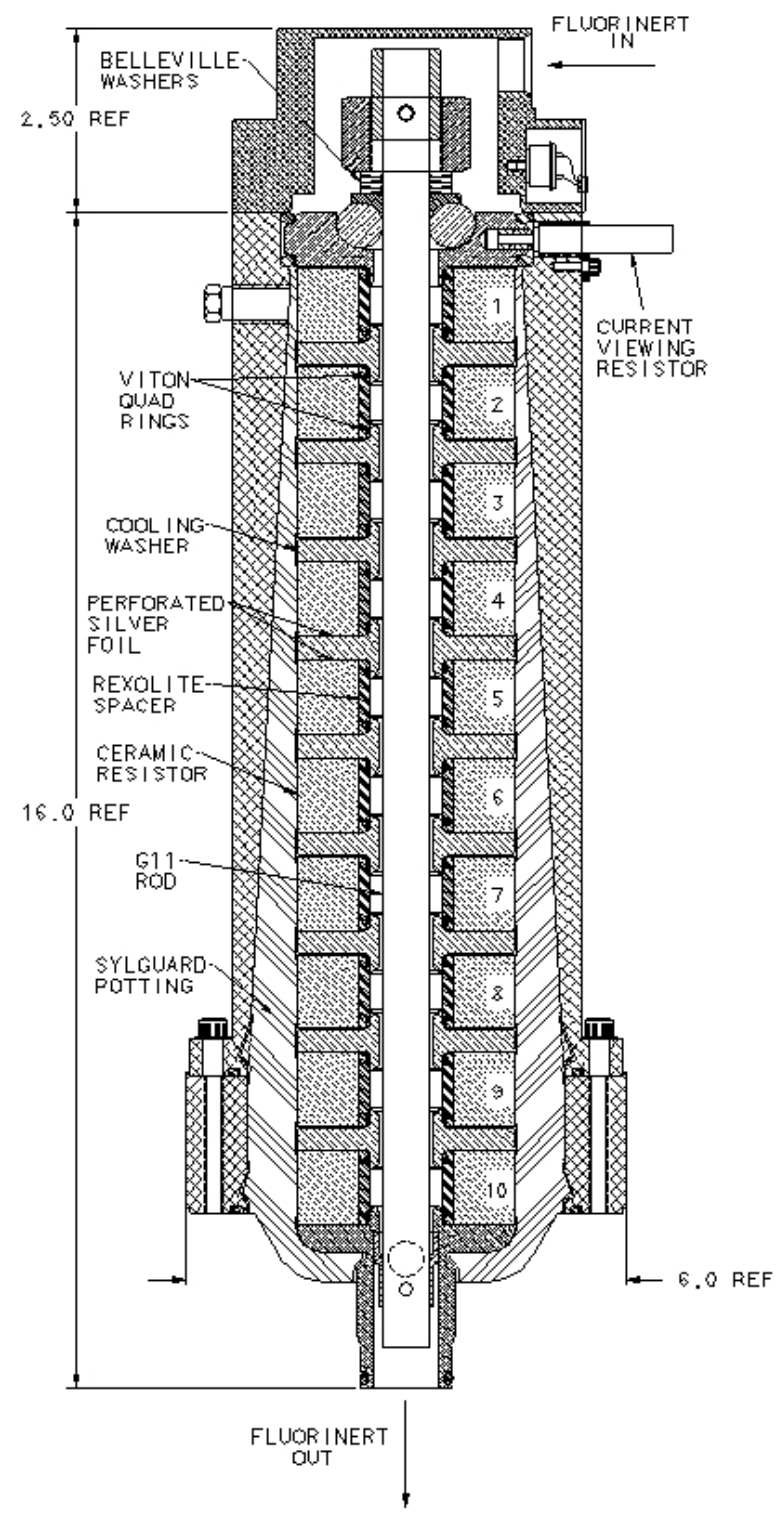

Figure 1. Magnet Termination Resistor Assembly

Prototype testing results showed the heat in the resistors was not being transferred efficiently enough to keep the resistance within specification so the cooling washer design was re-evaluated. Several design changes were investigated and prototypes tested. The four most effective were integrated into the final design, adding helical cooling fins to the washer I.D., increasing washer 
thickness, adding silver-filled conductive grease, and increasing the Fluorinert ${ }^{\circledR}$ flowrate. Prototype cooling washers with three different thicknesses were modeled in ANSYS [2], fabricated, and tested (see Figure 2 and Figure 3). It was found that three times the original thickness was the most effective size that would work within the size constraints determined by the relationship between the magnet and the concrete floor in the enclosure.

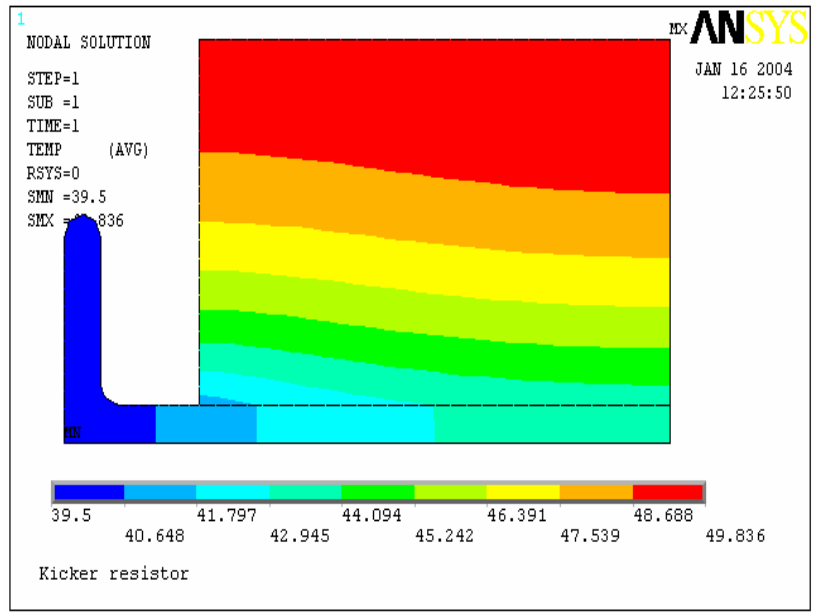

Figure 2.

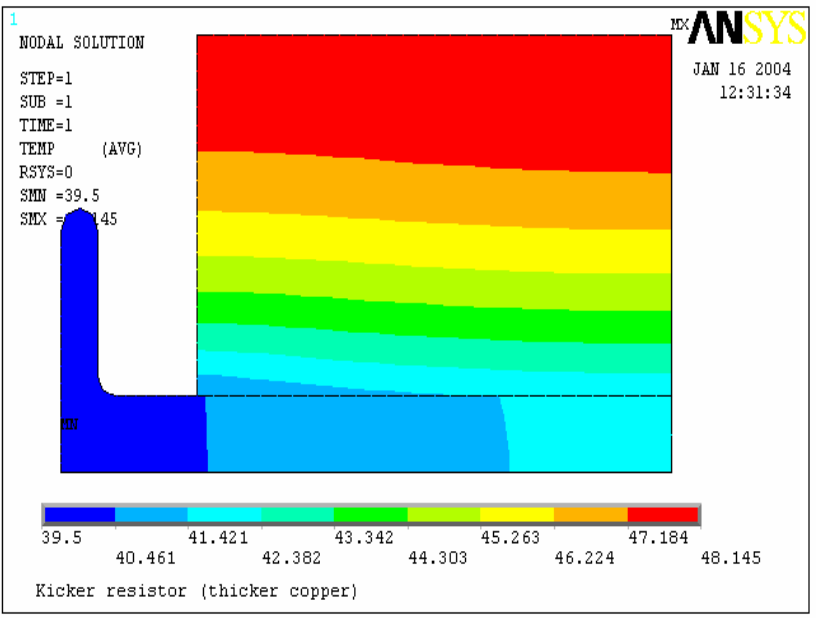

Figure 3.

The cooling fluid flows through a variable diameter annular channel. The initial design flowrate was 2.5 gallons per minute (gpm) but testing showed significant improvement at $5 \mathrm{gpm}$. This required the cross-sectional flow space be enlarged to lower the fluid velocity and minimize the erosion of the silver-plated helical cooling fins. Several designs were tested and a complex 80 -fin prototype worked best but was rejected as too costly to manufacture in the quantity needed. The helical fin detail used for the magnet was produced with a more cost effective method similar to cutting internal threads.

The resistor to washer interface was determined to be a high thermal impedance. To enhance the heat transfer and electrical contact between the ceramic resistor and silverplated copper surfaces $20-.012$ " thick perforated $99.97 \%$ pure silver foil discs were added. Testing showed that foil with $5 \%$ open area worked best in this application. The silver foil was lightly covered with silver-filled conductive grease to further reduce the thermal impedance. The final configuration has an impedance of $0.1 \mathrm{C} / \mathrm{W}$. This is now relatively small compared to the thermal impedance of the ceramic resistor itself, $\sim 0.25$ $\mathrm{C} / \mathrm{W}$ for this size and double sided cooling. The final resistor assembly temperature coefficient is $\sim-900$ $\mathrm{ppm} / \mathrm{C}$.

To isolate the resistors from the Fluorinert ${ }^{\circledR}$, Rexolite ${ }^{\circledR}$ spacers with grooves containing Viton ${ }^{\circledR}$ Quad-Rings ${ }^{\circledR}$ mate with the cooling washers (see Figure 1). QuadRings ${ }^{\circledR}$ were chosen because they offer twice the sealing surface of a standard O-ring and their mold parting lines are recessed, not on the surface of the seal. Viton ${ }^{\circledR}$ is specified for its chemical resistance and compatibility with Fluorinert ${ }^{\circledR}$ and is used for every seal in the system.

\section{FLUID PROCESSING SYSTEM}

As stated earlier, increased performance requirements necessitated adding a forced cooling system. This immediately led to the decision to use a Fluorinert ${ }^{\circledR}(\mathrm{FC}-$ 77) with a higher boiling point than used in the existing design to insure single-phase flow. After debating the relative merits of locating pumps inside the Main Injector enclosure, the decision was made to install the cooling system in a Main Injector Service Building (MI-60 South) 150 ' horizontally and $33^{\prime}$ 'vertically above the magnet. Difficulty with maintenance and repair of the pumps and the survivability of variable frequency drives in radiation drove the decision.

A fluid flow simulation software named SiNET was used to perform initial modeling of the system. Every effort was made in the design to operate the system at the lowest possible pressure. This was driven by the fact that Fluorinert ${ }^{\circledR}$ is very difficult to contain. It has low viscosity and surface tension combined with excellent surface wetting properties [3] and it costs $\sim \$ 400$ /gallon. The four load assemblies combined have over 100 elastomeric seals to contain the fluid and prevent the ceramic resistors from coming in contact with the Fluorinert ${ }^{\circledR}$. Any leak means the entire assembly must be rebuilt. The lower the system pressure, the lower the chance of developing a leak.

The loads are leak-checked and vacuum potted with a silicone compound (Sylgard $\left.{ }^{\circledR} 184\right)$. Before this step, each resistor is sealed with RTV to prevent drawing the potting material into the resistor/grease/cooling washer interface and to prevent trapped air from escaping into the potting.

Threaded joints were intentionally kept to a minimum. Compression fittings are used in many places and were satisfactory once we learned how much force is required to make gas-tight joints in 1" $\varnothing .083 "$ wall 316 SS tubing. The best fittings and most reliable to work with in this application were sanitary quick-clamp (tri-clamp) with Viton ${ }^{\circledR}$ gaskets.

When Fluorinert ${ }^{\circledR}$ is exposed to radiation, a small fraction breaks down into some corrosive compounds. 
Included in this fluid processing system are a series of filters designed to minimize their production and to remove them when formed. This is accomplished by removing water, the source of hydrogen needed to form the corrosive compounds, from the Fluorinert ${ }^{\circledR}$ by means of a molecular sieve. The primary filter is composed of activated alumina granules that have an affinity for the products of decomposition of Fluorinert ${ }^{\circledR}$. It was originally designed by $3 \mathrm{M}$ to protect Cray supercomputers. Because of the potential for accelerated corrosion of the system, sanitary grade $316 \mathrm{~L}$ SS tubing and automatic orbital welds were specified in the construction of the cooling system. Care was also taken to minimize any pockets of stagnant fluid.

Due to the unusual system performance requirements, low flow, high pressure, high specific gravity (1.8), and the ability to seal Fluorinert $\AA$, the typical centrifugal pump would not suffice. Chosen were canned motor, regenerative turbine pumps that are totally enclosed and liquid cooled. This type eliminates the rotary shaft seal leak path and is cooled by the process fluid Fluorinert ${ }^{\circledR}$. To aid in fine-tuning the system, variable frequency drives have been included. Currently, the system is operating at $85 \%$ of the capacity of the pumps.

When NuMI operates in different modes, it is desirable to vary the setpoint temperature of the cooling system and the resulting resistance of the loads. A PID controller, remotely operated, manages the chilled water flow through the heat exchanger and the power to the heater vessel. A heater was added because the heat generated in the loads and the pump was not sufficient to maintain higher setpoints even though the entire system is thermally insulated. The PID controller operates in duplex mode to balance heating and cooling.

The whole system has logged over 5 months of operation to date, is performing well, and meets specification [1].

\section{REFERENCES}

[1] C.C. Jensen, G.A. Krafczyk, "NuMI Proton Kicker Extraction System", PAC 2005

[2] Zhijing Tang, "Thermal Analysis of Kicker Magnet Resistor", Fermilab Internal Memo, January 23, 2004

[3] 3M Corporation website, http://products3.3m.com. 